\title{
Schottky Barrier Parameters and Interfacial Reactions of Rapidly Annealed Au/Cu Bilayer Metal Scheme on N-type InP
}

\author{
V. Lakshmi Devi ${ }^{1}$, I. Jyothi ${ }^{1}$, V. Rajagopal Reddy ${ }^{* 1}$ and Chel-Jong Choi ${ }^{2}$ \\ ${ }^{I}$ Department of Physics, Sri Venkateswara University, Tirupati-517 502, India \\ ${ }^{2}$ School of Semiconductor and Chemical Engineering, Semiconductor Physics Research Center (SPRC), Chonbuk \\ National University, Jeonju 561-756, Korea
}

\begin{abstract}
The influence of rapid thermal annealing effect on the electrical and structural properties of $\mathrm{Au} / \mathrm{Cu} \mathrm{Schottky}$ contacts on $\mathrm{n}$-InP has been investigated by the current-voltage (I-V), capacitance-voltage $(\mathrm{C}-\mathrm{V})$, auger electron spectroscopy (AES) and the X-ray diffraction (XRD) techniques. As-deposited sample has a barrier height of $0.64 \mathrm{eV}$ (I$\mathrm{V}), 0.76 \mathrm{eV}(\mathrm{C}-\mathrm{V})$ which increases to $0.82 \mathrm{eV}(\mathrm{I}-\mathrm{V}), 1.04 \mathrm{eV}(\mathrm{C}-\mathrm{V})$ after annealing at $400^{\circ} \mathrm{C}$ for $1 \mathrm{~min}$ in nitrogen ambient. However, the barrier height decreases to $0.75 \mathrm{eV}(\mathrm{I}-\mathrm{V}), 0.88 \mathrm{eV}(\mathrm{C}-\mathrm{V})$ after annealing at $600^{\circ} \mathrm{C}$ for $1 \mathrm{~min}$. Norde method is also employed to calculate the barrier heights of $\mathrm{Au} / \mathrm{Cu}$ Schottky rectifiers and the values are $0.66 \mathrm{eV}$ for as-deposited, $0.83 \mathrm{eV}$ for $400^{\circ} \mathrm{C}$ and $0.76 \mathrm{eV}$ for $600^{\circ} \mathrm{C}$ annealed contacts. These values are in good agreement with the values obtained from I-V method. From the above observations, it is clear that the Schottky barrier height increases with annealing temperatures up to $400^{\circ} \mathrm{C}$. Thus, the optimum annealing temperature for the $\mathrm{Au} / \mathrm{Cu}$ Schottky contact is $400^{\circ} \mathrm{C}$. Based on the AES and XRD results, the formation of indium phases at the $\mathrm{Au} / \mathrm{Cu} / \mathrm{n}$ - InP interface may be responsible for the increase in the barrier height for the contact annealed at $400^{\circ} \mathrm{C}$ and a corresponding decrease in leakage current. The decrease in the barrier height after annealing at $500{ }^{\circ} \mathrm{C}$ may be due to the formation of $\mathrm{Cu}-\mathrm{P}$ and $\mathrm{Au}-\mathrm{P}$ interfacial compounds at the interface. The AFM results showed that the surface morphology of $\mathrm{Au} / \mathrm{Cu}$ Schottky contact is fairly smooth even after annealing at $500^{\circ} \mathrm{C}$.
\end{abstract}

PACS 61.05.cp, 68.37.Ps, 73.30.+y, 73.40.Kp, 85.30.Hi, 85.30.Kk.

Keywords: $\mathrm{Au} / \mathrm{Cu}$ Schottky contacts; n-type InP, electrical and structural properties, barrier height, auger electron spectroscopy, X-ray diffraction.

\section{INTRODUCTION}

Group III-V compound semiconductors, particularly, indium phosphide (InP) are promising materials for the fabrication of high-speed electronic and optoelectronic devices due to their large band gap, high electron mobility, high saturation velocity and break down voltage, which are important in electron devices [1-6]. Metal-semiconductor (MS) contact is one of the most widely used rectifying contacts in the electronics industry [2-4]. However, the fabrication of InP Schottky barrier devices has been hindered by inherently low barrier heights (BHs) of Schottky contacts, poor stability, and a large reverse leakage current. So far Schottky metal contacts to $\mathrm{n}$-InP have been investigated which yielded barrier heights in the range of $0.3-0.5 \mathrm{eV}$ [7-9]. Such a low barrier height is detrimental to the device performance and it is, therefore, desirable to develop techniques to enhance the barrier height. The barrier height is likely to be a function of the atomic inhomogeneities and the interface atomic structure at metalsemiconductor (MS) interface which are caused by grain boundaries, multiple phases, facets, defects, a mixture of different phases, etc. [10-15]. The main technological issue in the study of semiconductor interface is the continuous control of

*Address correspondence to this author at the Department of Physics, Sri Venkateswara University, Tirupati-517 502, India; Tel: +91 9490271646; Emails: reddy_vrg@rediffmail.com,dr_vrg@rediffmail.com the barrier height $(\mathrm{BH})$ of high quality Schottky barrier diodes (SBDs) with low departure of ideality factor (n) from unity. Therefore, the development of high-quality Schottky contacts to InP with high barrier height, low-leakage current and good thermal stability is still a challenge.

The electrical and structural properties of the Schottky contacts on n-type InP have been investigated by several research groups [16-24]. Eftekhari [16] investigated the effect of rapid thermal annealing (RTA) on the electrical properties of $\mathrm{Ni}$ and $\mathrm{Pd}$ contacts on $\mathrm{n}-\mathrm{InP}$. Results showed that annealing the contacts at $450^{\circ} \mathrm{C}$ for $100 \mathrm{~s}$ has little effect on their electrical parameters. They also reported that the electrical characteristics of the contacts degraded after annealing at $600^{\circ} \mathrm{C}$. Huang et al., [17] fabricated a highperformance double metal structure using $\mathrm{Pt}$ and $\mathrm{Al}$ as Schottky contacts on n-InP and reported an effective barrier height of $0.74 \mathrm{eV}$ and ideality factor of 1.11 . They also found that the $\mathrm{Al}_{2} \mathrm{O}_{3}$ thin film was located at the interface of the $\mathrm{Pt} / \mathrm{Al} / \mathrm{n}$-InP diode by secondary ion-mass spectrum (SIMS) analysis. Jeng et al., [18] investigated the Ni Schottky contact on n-InP and showed that the barrier height was improved after inserting a thin praseodymium interlayer. Chen and Chou [19] studied the hydrogen sensing performance of $\mathrm{Pd} / \mathrm{n}$-InP Schottky diodes and found that the changes in the Schottky barrier height and ideality factor were increased with the increase of hydrogen concentration. 
Cetin and Ayyildiz [20] fabricated $\mathrm{Au}, \mathrm{Al}$ and $\mathrm{Cu} / \mathrm{n}-\mathrm{InP}$ Schottky diodes on chemically cleaned and air-exposed nInP surfaces and studied the influence of air-grown oxide on electrical performance. They found that the Schottky barrier height was more enhanced for the air-grown oxide Schottky barrier diode than the Schottky barrier diode without oxide layer. Bhaskar Reddy et al., [21] investigated the effects of rapid thermal annealing on the electrical and structural properties of Pd/Au Schottky contacts on n-type InP. They reported that the formation of indium phases at the interface could be the reason for the increase in Schottky barrier height at $400^{\circ} \mathrm{C}$. Janardhanam et al., [22] fabricated Mo Schottky diode on n-InP and investigated the electrical, structural and surface morphological properties as a function of annealing temperature. They reported that the decrease in barrier height after annealing at $500^{\circ} \mathrm{C}$ may be due to the formation of phosphide phases at the interface. Recently, Cetin et al., [23] fabricated $\mathrm{Au}$ and $\mathrm{Cu} / \mathrm{n}$-InP Schottky barrier diodes and reported that the effective barrier height of the $\mathrm{Au}$ and $\mathrm{Cu}$ Schottky contacts were $0.480 \mathrm{eV}, 0.404 \mathrm{eV}$ and $0.524 \mathrm{eV}, 0.453 \mathrm{eV}$ from $\mathrm{I}-\mathrm{V}$ and $\mathrm{C}-\mathrm{V}$ measurements. Very recently, Sankar Naik et al., [24] investigated the rapid thermal annealing effects on the electrical and structural properties of $\mathrm{Ni} / \mathrm{V}$ Schottky contacts on $\mathrm{n}-\mathrm{InP}$. They reported that the barrier heights were effectively influenced by rapid thermal annealing.

In this article, we fabricate and characterize the $\mathrm{Au} / \mathrm{Cu}$ Schottky contacts on n-type InP. Even though many kinds of metals are prepared on InP as Schottky contacts, to the best of our knowledge, $\mathrm{Au} / \mathrm{Cu}$ metal scheme has not been performed yet. In this work, copper $(\mathrm{Cu})$ is selected as a first layer because it is a very diffusive metal. Also, $\mathrm{Cu}$ possesses excellent electrical and thermal conductivities, and has demonstrated high electron migration resistance in $\mathrm{Si}$ integrated circuits and GaAs monolithic microwave integrated circuits [25]. These advantages make $\mathrm{Cu}$ a promising possible Schottky metal for the InP semiconductor. $\mathrm{Au}$ is selected as a second layer over $\mathrm{Cu}$ layer in order to prevent oxidation as well as to promote current spreading in the contact and to provide good smoothness to the contact. There is a serious lack of information about the effect of annealing, especially the rapid thermal annealing (RTA) on the electrical and structural properties of metal/InP Schottky contacts. Therefore, our main focus in this work is to investigate the electrical, structural and surface morphological characteristics of $\mathrm{Au} / \mathrm{Cu}$ Schottky contacts on $\mathrm{n}-\mathrm{InP}$ as a function of annealing temperature.

\section{EXPERIMENTAL PROCEDURE}

The metal-semiconductor $(\mathrm{Au} / \mathrm{Cu} / \mathrm{n}$-InP) Schottky diodes are fabricated on undoped one side polished n-type InP which is grown by Liquid Encapsulated Czochralski (LEC) with carrier concentration of $4.5 \times 10^{15} \mathrm{~cm}^{-3}$. The substrate is sequentially cleaned with organic solvents like trichloroethylene, acetone and methanol by means of ultrasonic agitation in sequence for $5 \mathrm{~min}$ to remove contaminants followed by rinsed in de-ionized (DI) water and dried in $\mathrm{N}_{2}$ flow. The samples are then etched with HF
(49\%) and $\mathrm{H}_{2} \mathrm{O}$ (1:10) for 1 min to remove the native oxides from the wafer surface. To make ohmic contacts, indium (In) metal is deposited with thickness of $500 \AA$ on the rough side of the $\mathrm{InP}$ wafer followed by annealing at $350^{\circ} \mathrm{C}$ for $1 \mathrm{~min}$ in $\mathrm{N}_{2}$ atmosphere. The Schottky metal contacts are made by evaporating $\mathrm{Cu}(20 \mathrm{~nm})$ and $\mathrm{Au}(30 \mathrm{~nm})$ on the smooth surface of $n-I n P$ as dots with a mask of diameter about $0.7 \mathrm{~mm}$. The entire evaporation process is carried out in an electron beam evaporation unit at about $4 \times 10^{-6}$ pressure. Metal layer thickness and deposition rates are monitored with the help of a digital quartz crystal thickness monitor. The deposition rates are about 3-5 $\AA / \mathrm{s}$. The bilayer structure of $\mathrm{Au} / \mathrm{Cu} / \mathrm{n}-\mathrm{InP}$ Schottky diodes used in this study is shown in Fig. (1). The current-voltage (I-V) and capacitancevoltage $(\mathrm{C}-\mathrm{V})$ characteristics of the $\mathrm{Au} / \mathrm{Cu}$ Schottky contacts are measured using a Keithley source measure unit (Model No. 2400) and automated deep level spectrometer (SEMILAB DLS-83D) at room temperature. To investigate interdiffusion between $\mathrm{Au} / \mathrm{Cu}$ and $\mathrm{n}$-InP layers, auger electron microscopy (AES: VG: Microlab 350) depth profiling is employed. X-ray diffraction (Siefert XRD PW 3710 ) is used to characterize the interfacial reactions between the metal and InP layers. Atomic force microscopy (AFM) is also employed to characterize the surface morphology of the samples before and after annealing.

\section{Bilayer Schottky contact}

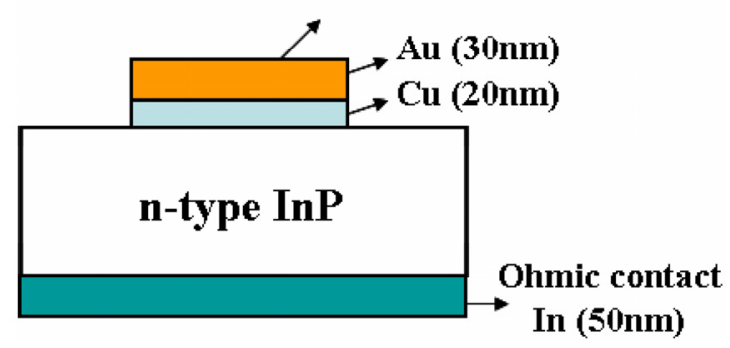

Fig. (1). Schematic diagram of the bilayer metal scheme $\mathrm{Au} / \mathrm{Cu}$ on n-type InP.

\section{RESULTS AND DISCUSSION}

The forward and reverse current-voltage (I-V) characteristics of the $\mathrm{Au} / \mathrm{Cu}$ Schottky contacts are shown in Fig. (2) before and after annealing at $600^{\circ} \mathrm{C}$. It is observed that the reverse leakage current of the as-deposited is found to be $6.597 \times 10^{-7}$. However, the reverse leakage current decreases for the contacts annealed at $200^{\circ} \mathrm{C}, 300^{\circ} \mathrm{C}$ and $400^{\circ} \mathrm{C}$ and the values are $3.1583 \times 10^{-7}, 9.8390 \times 10^{-8}$ and $1.1140 \times 10^{-9} \mathrm{~A}$ at $-1 \mathrm{~V}$. Further, it is noted that the leakage current increases with an increase in the annealing temperature. When the contact is annealed at temperature of $600^{\circ} \mathrm{C}$, the leakage current increases to $1.0795 \times 10^{-8} \mathrm{~A}$ at $1 \mathrm{~V}$. The ideality factor $\mathrm{n}$ and the Schottky barrier height (SBH) of the Schottky diode are evaluated by using the following equation based on the thermionic emission theory [26].

$$
I=A A^{* * *} T^{2} \exp \left(\frac{-q \varphi_{b}}{k T}\right)\left[\exp \left(\frac{q V}{n k T}\right)-1\right]
$$


or $I=I_{0} \exp \left(\frac{q V}{n k T}-1\right)$ for $\mathrm{V}>3 \mathrm{kT} / \mathrm{q}$

where $\mathrm{A}$ is the contact area, $\mathrm{V}$ is the applied voltage drop across the rectifying barrier, $\mathrm{T}$ is the absolute temperature in Kelvin, $\mathrm{n}$ is the ideality factor and $\mathrm{I}_{\mathrm{o}}$ is the saturation current given by

$I_{O}=A A^{* *} T^{2} \exp \left(\frac{-q \varphi_{b}}{k T}\right)$

where $\mathrm{A}^{* *}\left(9.4 \mathrm{~A} \mathrm{~cm}^{-2} \mathrm{~K}^{-2}\right)$ [3] is the effective Richardson constant and $\phi_{\mathrm{b}}$ the barrier height at zero bias. The barrier height can be obtained from the equation

$\varphi_{b}=\frac{k T}{q} \ln \left(\frac{A A^{* *} T^{2}}{I_{O}}\right)$

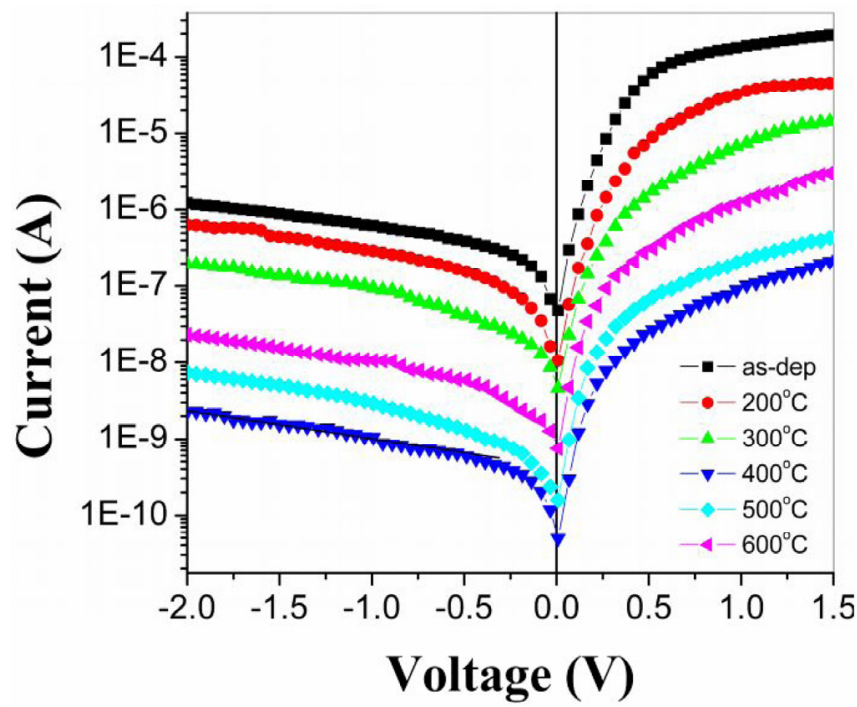

Fig. (2). Forward and reverse bias $\mathrm{I}-\mathrm{V}$ characteristics of $\mathrm{Au} / \mathrm{Cu} / \mathrm{n}$ InP Schottky diodes as a function of annealing temperature.

By fitting a linear curve to the forward I-V characteristics using the TE model, the Schottky barrier height $(\mathrm{SBH})\left(\phi_{\mathrm{b}}\right)$ and ideality factor (n) of the Schottky contact can be determined from the y-intercept and the slope of the fitted curve, respectively. The calculated value of $\phi_{\mathrm{b}}$ from the $\mathrm{I}-\mathrm{V}$ characteristics under dark condition is $0.64 \mathrm{eV}$ for the asdeposited sample. It is observed that the $\mathrm{SBH}$ increases for the contacts annealed at $200^{\circ} \mathrm{C}, 300^{\circ} \mathrm{C}$ and $400^{\circ} \mathrm{C}$ and the corresponding values are $0.68 \mathrm{eV}, 0.70 \mathrm{eV}$ and $0.82 \mathrm{eV}$, respectively. However, the barrier height slightly decreases for the contacts annealed at 500 and $600^{\circ} \mathrm{C}$ and the values are $0.80 \mathrm{eV}$ and $0.75 \mathrm{eV}$, respectively. According to Duboz et al., [27], the lower value of the barrier height for the sample annealed at a higher temperature can be attributed to a reduction in the density of interfacial defects. The modification of the defect density by annealing could change the pinning at the Fermi level, resulting in a change of the barrier heights. From the above observations, the barrier height increases with an increase in annealing temperature up to $400^{\circ} \mathrm{C}$ compared to the as-deposited and annealed at $200^{\circ} \mathrm{C}$ and $300^{\circ} \mathrm{C}$ contacts. Thus, the optimum annealing temperature for the $\mathrm{Au} / \mathrm{Cu}$ Schottky contact is $400^{\circ} \mathrm{C}$. The ideality factor $\mathrm{n}$ is defined as

$n=\left(\frac{q}{k T}\right)\left(\frac{d V}{d(\ln I)}\right)$

The ideality factor $\mathrm{n}$ can be determined from the slope of linear region of semilog forward I-V plots using the above equation. The ideality factor of $\mathrm{Au} / \mathrm{Cu}$ Schottky contact is found to be 1.74 for the as-deposited sample. The estimated values of the ideality factor $\mathrm{n}$ are $1.68,1.65,1.32,1.44$ and 1.51 for the contacts annealed at $200^{\circ} \mathrm{C}, 300^{\circ} \mathrm{C}, 400^{\circ} \mathrm{C}$, $500^{\circ} \mathrm{C}$ and $600^{\circ} \mathrm{C}$ respectively. Our results show that the ideality factors of $\mathrm{Au} / \mathrm{Cu}$ Schottky contacts are higher than the unity. For an ideal diode, the diode ideality factor $n$ should be nearly equal to unity. But in a real situation, it may increase when the effects of series resistance, leakage current, etc., come into play. The high values in the ideality factor are caused possibly by various effects such as inhomogeneities of film thickness, interface states, series resistance, tunneling process and non-uniformity distribution of the interfacial charges. A high ideality factor is often attributed to defect states in the semiconductor band gap [11]. As the annealing temperature rises, the amount of transferred charge increases, which creates more defects in the InP close to the interface and inside the interfacial layer. These defects could be responsible for the increase in value of the ideality factor. In the case of the interface layer, interface states and fixed surface charge effects of the reverse and forward bias characteristics of Schottky devices deviate the ideal Schottky diode characteristics. Therefore, it can be said that the performance and reliability of Schottky devices depend on the interface layer and fixed surface charge. The interface states play an important role in the determination of metal/semiconductor structures. The higher values of ideality factors are attributed to secondary mechanisms that include interface dipoles due to interface doping or specific interface structure as well as fabricationinduced defects at the interface $[28,29]$. According to Tung [30], the high values of $\mathrm{n}$ can also be attributed to the presence of a wide distribution of low-SBH patches caused by laterally inhomogeneous barrier. Also, the image-force effect, recombination generation, and tunneling may be possible mechanisms that could lead to the ideality factor value greater than unity [6].

The series resistance $R_{s}$ of the diode is calculated from I$\mathrm{V}$ measurement using a method developed by Cheung and Cheung [31]. Generally, the forward bias current-voltage characteristics are linear on a semi logarithmic scale at low forward bias voltages but deviate considerably from linearity due to the effect of series resistance $R_{s}$ and other effects. The forward bias current-voltage characteristics due to thermionic emission of a Schottky contact with the series resistance can be expressed by Cheung's function given by

$\frac{d V}{d(\ln I)}=I R_{s}+n\left(\frac{k T}{q}\right)$

Fig. (3) shows the plots of experimental $\mathrm{dV} / \mathrm{d} \ln (\mathrm{I})$ vs I for different annealing temperatures. The series resistance values 
are obtained from the slope and nkT/q value from the $\mathrm{y}$ intercept. The calculated series resistance Rs of the asdeposited and annealed $\mathrm{Au} / \mathrm{Cu}$ Schottky contacts is in the range $\mathrm{Rs}=307$ to $1787 \Omega$. A high series resistance can hinder an accurate evaluation of barrier height from the standard $\ln (\mathrm{I})-\mathrm{V}$ plot. For that reason, the Norde method [32] is also employed to compare the effective Schottky barrier height of $\mathrm{Au} / \mathrm{Cu}$ Schottky contacts. The method involves a Norde function, $\mathrm{F}(\mathrm{V})$, being plotted against $\mathrm{V}$ (plot not shown here). $F(V)$ is given by $F(V)=V / 2$ $(k T / q) \ln \left[I(V) / A A^{* *} T^{2}\right]$. The effective SBH is given by $\phi_{b}=$ $F\left(V_{\min }\right)+V_{\min } / 2-k T / q$, where $F\left(V_{\text {min }}\right)$ is the minimum value of $F(V)$ and $V_{\min }$ is the corresponding voltage. The extracted Schottky barrier heights are $0.66 \mathrm{eV}$ for as-deposited, $0.70 \mathrm{eV}$ at $200^{\circ} \mathrm{C}, 0.72 \mathrm{eV}$ at $300^{\circ} \mathrm{C}, 0.83 \mathrm{eV}$ at $400^{\circ} \mathrm{C}, 0.81 \mathrm{eV}$ at $500^{\circ} \mathrm{C}$ and $0.76 \mathrm{eV}$ at $600^{\circ} \mathrm{C}$. It is observed that these values are in good agreement with those obtained by the I-V method.

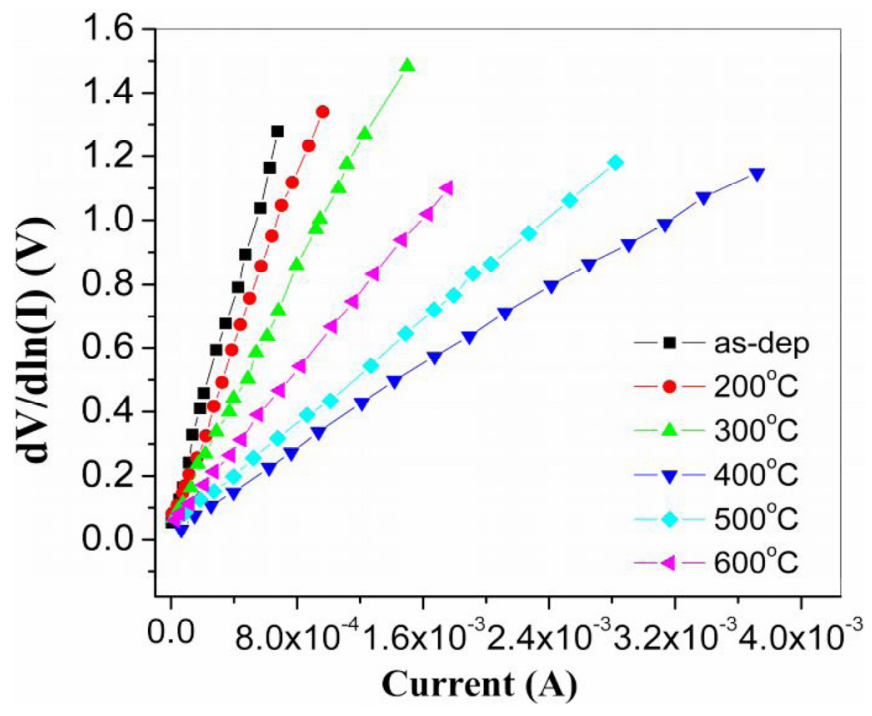

Fig. (3). Plot of $\mathrm{dV} / \mathrm{d} \ln (\mathrm{I})$ vs I for $\mathrm{Au} / \mathrm{Cu}$ Schottky contacts to $\mathrm{n}-\mathrm{InP}$ annealed at different temperatures.

Capacitance-voltage $(\mathrm{C}-\mathrm{V})$ measurements are normally used to determine the effective Schottky barrier height of a MS diode. The capacitance-voltage $(\mathrm{C}-\mathrm{V})$ characteristics of $\mathrm{Au} / \mathrm{Cu}$ Schottky are measured as a function of annealing temperature. The $\mathrm{C}-\mathrm{V}$ measurements are performed at
1MHz. Fig. (4) shows a plot of $1 / \mathrm{C}^{2}$ as a function of bias voltage for as-deposited and annealed $\mathrm{Au} / \mathrm{Cu}$ Schottky contacts. The C-V relationship of Schottky diode is given by [6]

$$
\frac{1}{C^{2}}=\left(\frac{2}{\mathcal{E}_{s} q N_{d} A^{2}}\right)\left(V_{b i}-\frac{k T}{q}-V\right)
$$

where $\varepsilon_{\mathrm{s}}$ is the permittivity of the semiconductor $\left(\varepsilon_{\mathrm{s}}=11 \varepsilon 0\right)$, $\mathrm{N}_{\mathrm{d}}$ is the donor concentration, $\mathrm{A}$ is the area of the Schottky contact and $\mathrm{V}_{\mathrm{bi}}$ is the flat band voltage. The $\mathrm{x}$-intercept of $\left(1 / \mathrm{C}^{2}\right)$ vs $\mathrm{V}$ plot yields $\mathrm{V}_{\mathrm{o}} ; \mathrm{V}_{\mathrm{o}}$ is related to the built-in potential $\mathrm{V}_{\mathrm{bi}}$ by the equation $\mathrm{V}_{\mathrm{bi}}=\mathrm{V}_{\mathrm{o}}+\mathrm{kT} / \mathrm{q}$, where $\mathrm{T}$ is the absolute temperature. The barrier height $\left(\phi_{\mathrm{b}}\right)$ is given by $\phi_{\mathrm{b}}=$ $\mathrm{V}_{\mathrm{bi}}+\mathrm{V}_{\mathrm{n}}$, where $\mathrm{V}_{\mathrm{n}}=(\mathrm{kT} / \mathrm{q}) \ln \left(\mathrm{N}_{\mathrm{c}} / \mathrm{N}_{\mathrm{d}}\right)$. The density of states in the conduction band edge is given by $\mathrm{N}_{\mathrm{c}}=$ $2\left(2 \pi \mathrm{m}^{*} \mathrm{kT} / \mathrm{h}^{2}\right)^{3 / 2}$, where $\mathrm{m}^{*}=0.078 \mathrm{~m}_{\mathrm{o}}$ [6] and its value is $5.7 \times 10^{17} \mathrm{~cm}^{-3}$ for InP at room temperature. The estimated donor concentrations of $\mathrm{Au} / \mathrm{Cu}$ Schottky contacts from the slope of the curves in Fig. (4) are $6.3178 \times 10^{15} \mathrm{~cm}^{-3}$ for the as-deposited, $\quad 5.8961 \times 10^{15} \mathrm{~cm}^{-3}, \quad 5.4688 \times 10^{15} \mathrm{~cm}^{-3}$, $4.5577 \times 10^{15} \mathrm{~cm}^{-3}, 5.1239 \times 10^{15} \mathrm{~cm}^{-3}$ and $5.1973 \times 10^{15} \mathrm{~cm}^{-3}$ for the samples annealed at $200,300,400,500$ and $600^{\circ} \mathrm{C}$ respectively. Generally, the capacitance measured for the Schottky diode is dependent on the bias voltage and signal frequency. Since the capacitance-voltage measurements are made at high frequencies $(1 \mathrm{MHz})$, the interface state charges do not contribute to the diode capacitance. The calculated barrier heights of $\mathrm{Au} / \mathrm{Cu}$ Schottky contacts from $\mathrm{C}-\mathrm{V}$ measurements are $0.76 \mathrm{eV}$ for as-deposited, $0.83 \mathrm{eV}$ for $200^{\circ} \mathrm{C}, 0.93 \mathrm{eV}$ for $300^{\circ} \mathrm{C}, 1.04 \mathrm{eV}$ for $400^{\circ} \mathrm{C}, 0.96 \mathrm{eV}$ for $500^{\circ} \mathrm{C}$ and $0.88 \mathrm{eV}$ for $600^{\circ} \mathrm{C}$ annealed contacts. It is noted that the Schottky barrier height increases with annealing temperature up to $400^{\circ} \mathrm{C}$, whereas the contacts annealed at higher annealing temperature $\left(500^{\circ} \mathrm{C}\right.$ and $\left.600^{\circ} \mathrm{C}\right)$, the Schottky barrier heights decreases. The observed values of reverse leakage currents, Schottky barrier heights and ideality factors of $\mathrm{Au} / \mathrm{Cu}$ Schottky diodes as a function of annealing temperature are given in Table 1. According to I$\mathrm{V}$, Norde and $\mathrm{C}-\mathrm{V}$ measurements the barrier heights are enhanced with an increase in the annealing temperatures up to $400^{\circ} \mathrm{C}$. This may be due to $\mathrm{Au} / \mathrm{Cu}$ metal layers that react with the InP, as will be confirmed by AES and XRD

Table 1. The Leakage Current, Schottky Barrier Heights and Ideality Factor of Au/Cu/n-InP Schottky Diode as a Function of Annealing Temperature

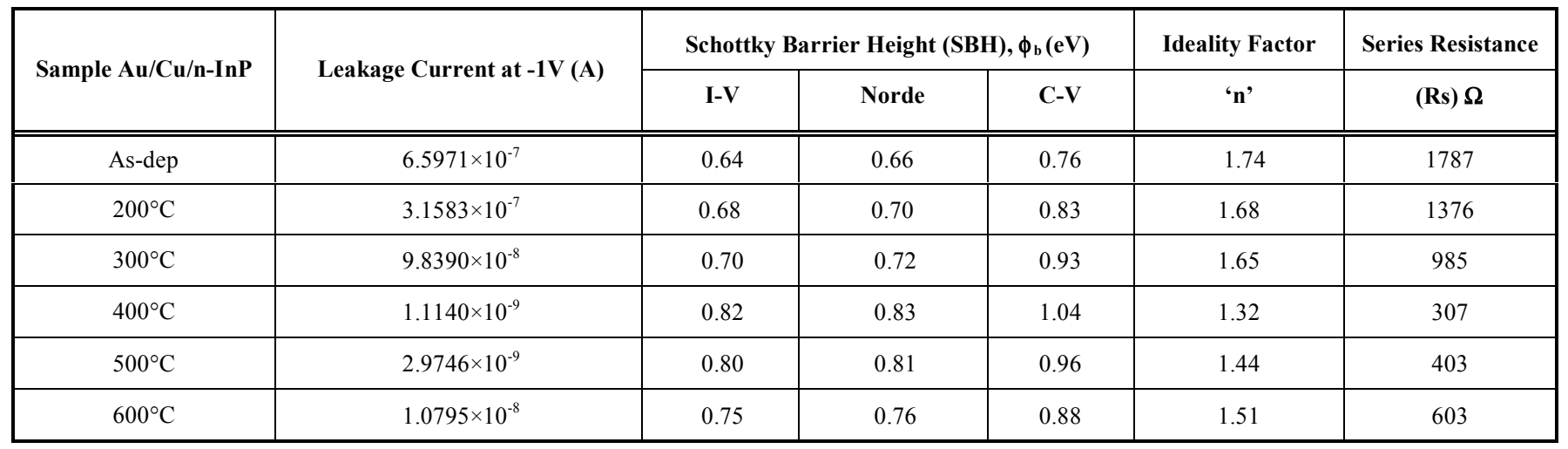


examinations.

Fig. (5) shows the plot of barrier heights obtained from $\mathrm{Au} / \mathrm{Cu}$ Schottky contacts in different methods (I-V, Norde and $\mathrm{C}-\mathrm{V}$ ) as a function of annealing temperature. It can be observed that the barrier height of the as-deposited $\mathrm{Au} / \mathrm{Cu}$ Schottky diode increases with the increase in annealing temperature. It is observed from Fig. (5) that the contact annealed at $400^{\circ} \mathrm{C}$ is having higher barrier height as compared with that of the as-deposited contact and annealed at $500^{\circ} \mathrm{C}$ and $600^{\circ} \mathrm{C}$ contacts. However, the Schottky barrier height decreases after annealing at $500^{\circ} \mathrm{C}$ and $600^{\circ} \mathrm{C}$. The increase in the barrier height at higher temperatures may be due to the interface states and chemical reactions between the metal and the semiconductor.

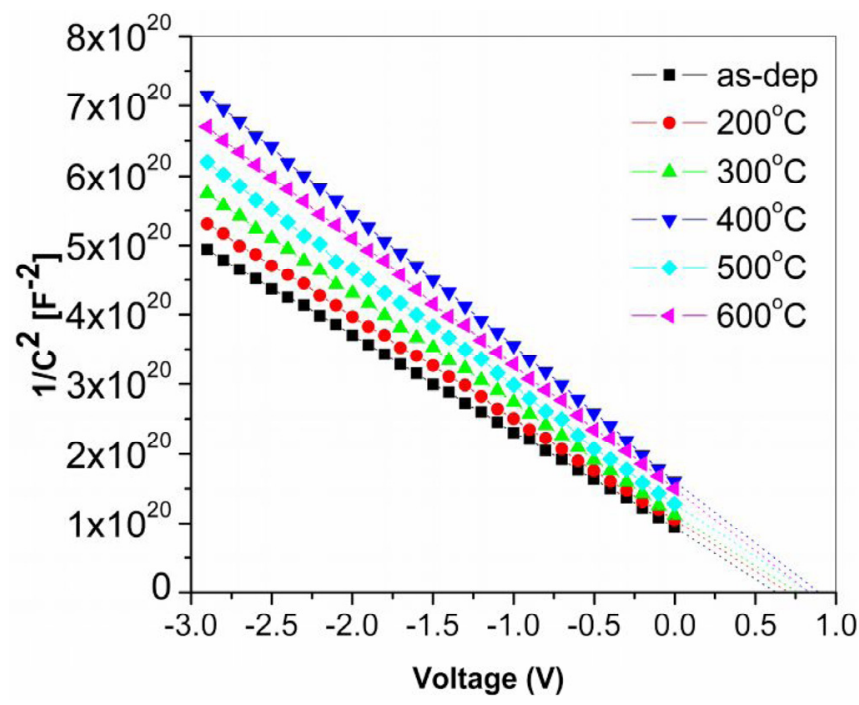

Fig. (4). Reverse bias $1 / \mathrm{C}^{2} v s \mathrm{~V}$ characteristics of $\mathrm{Au} / \mathrm{Cu} / \mathrm{n}-\mathrm{InP}$ Schottky diodes annealed at different temperatures.

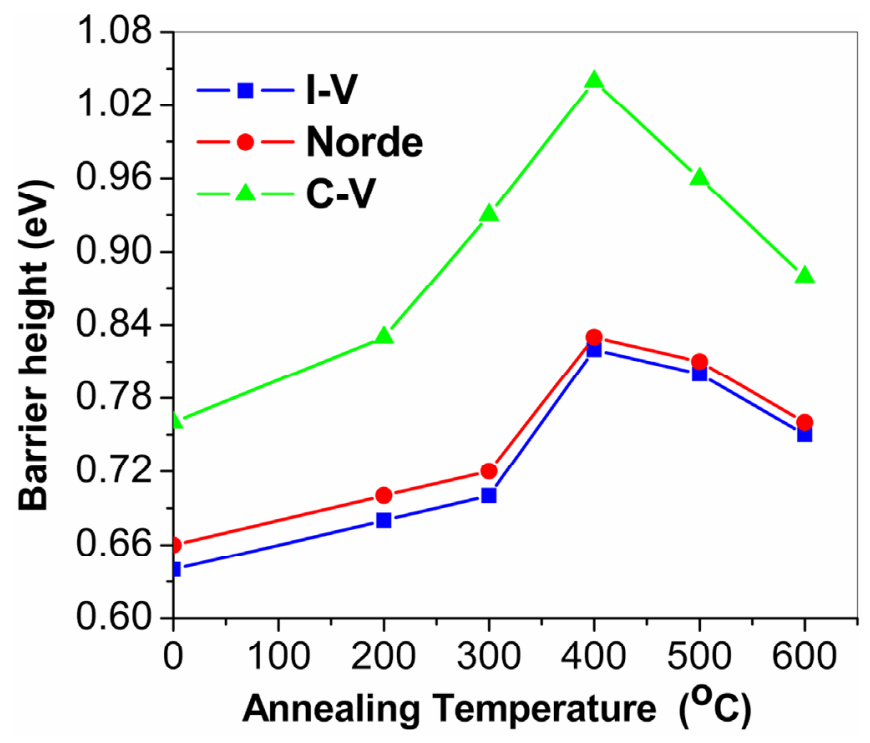

Fig. (5). Plot of barrier heights of $\mathrm{Au} / \mathrm{Cu} / \mathrm{n}$-InP Schottky diodes as a function of annealing temperatures.

It can also be seen from Fig. (5), the barrier heights, $\phi_{\mathrm{b}}$, obtained from I-V measurements are lower than those obtained from $\mathrm{C}-\mathrm{V}$ measurements. This discrepancy between $\phi_{\mathrm{b}}(\mathrm{I}-\mathrm{V})$ and $\phi_{\mathrm{b}}(\mathrm{C}-\mathrm{V})$ for metal/InP Schottky diodes could be explained as follows. At a high annealing temperature, the reactions products may not be uniform at the interface. The type and reaction phases may vary from one location to another, resulting in a different barrier height. This may be due to inhomogeneity at the interface [33, 34]. The difference may also be due to the formation of an interfacial layer containing defects. Thus, interfacial capacitance and capacitance due to depletion layer are in series, thereby as decreasing in the total capacitance and as a result, $\mathrm{C}^{-2}$ increases. This increases the intercept of $\mathrm{C}^{-2} v s \mathrm{~V}$ plot and increases the barrier height which may be due to the transport mechanism in these diodes and it is not purely thermionic emission in nature. Another reason may be the lowering of barrier height by the image force due to current flow across the barrier [11]. In view of the fact that the I-V method involves the flow of electrons from semiconductor to the metal, the barrier height determined from the I-V method will logically yield lower barrier heights or a combination of low and high barrier heights than barrier heights values from $\mathrm{C}-\mathrm{V}$ method. This is known as parallel [35] or mixed phase [36] contact. Another possibility is that the capacitance $\mathrm{C}$ is insensitive to potential fluctuations at a length scale of less than the space charge width $[37,38]$. The dc current I across the interface depend exponentially on $\phi_{\mathrm{b}}$ and is thus sensitive to the detailed barrier distribution at the interface. Thus, for an inhomogeneous interface, spatial variations of band bending $V_{d}$ and $\phi_{b}$ result in different Schottky barrier heights for the current and capacitance. Furthermore, the $\mathrm{C}-\mathrm{V}$ technique averages over the whole area and measure the barrier height of Schottky diode. In contrast, the barrier height from the I-V method includes any barrier lowering effect due to the interfacial insulator layer or the interface states, and effective barrier height is measured. Moreover, the determination of Schottky barrier height from I-V characteristics is only reliable if one can be confident that the current is determined by the TE theory. To do this, the forward portion of the characteristics should be a good straight line with a low value of ideality factor [2, 30, 39]. For the $\mathrm{Au} / \mathrm{Cu} / \mathrm{n}$-InP diodes, the $\phi_{\mathrm{b}}$ obtained from I-V method is voltage or electric field sensitive, whereas the $\phi_{\mathrm{b}}$ obtained from $\mathrm{C}-\mathrm{V}$ is not.

In order to investigate the interfacial reaction between $\mathrm{Au} / \mathrm{Cu}$ metal layers and InP film, the AES depth profile is employed. Fig. (6) shows the AES depth profiles of the $\mathrm{Au} / \mathrm{Cu}$ Schottky contact before and after annealing at $500^{\circ} \mathrm{C}$ for $1 \mathrm{~min}$ under $\mathrm{N}_{2}$ ambient. For the as-deposited $\mathrm{Au} / \mathrm{Cu} / \mathrm{n}$ InP Schottky diode, Fig. (6a), the metal layers ( $\mathrm{Au}$ and $\mathrm{Cu})$ exhibit a relatively sharp interface, indicating the absence of interdiffusion into InP. Fig. (6b) shows the AES depth profile of the $\mathrm{Au} / \mathrm{Cu}$ contact annealed at $400^{\circ} \mathrm{C}$. When the contact annealing temperature at $400^{\circ} \mathrm{C}$, the AES depth profile shows that In is out diffused into $\mathrm{Au} / \mathrm{Cu}$ films. This indicates that the possibility of the reaction between $\mathrm{Au} / \mathrm{Cu}$ and In films, resulting in the formation of $\mathrm{Au}-\mathrm{In}$ and $\mathrm{Cu}-\mathrm{In}$ interfacial phases at the interface. For the contact annealed at $500^{\circ} \mathrm{C}$, Fig. (6c), a considerable change in the interface is observed with further outdiffusion of In into $\mathrm{Au} / \mathrm{Cu}$ metal layers. It is also noted that a small amount of $\mathrm{P}$ is outdiffused 
into metal layers. This indicates the possibility of $\mathrm{P}$ reaction with $\mathrm{Cu}$ and $\mathrm{Au}$, as a result the formation of $\mathrm{Cu}-\mathrm{P}$ and $\mathrm{Au}-\mathrm{P}$ interfacial phases at the interface. Moreover, it is observed that a small amount of oxygen is observed in the interface for all contacts. This may have partially originated from the InP surface.
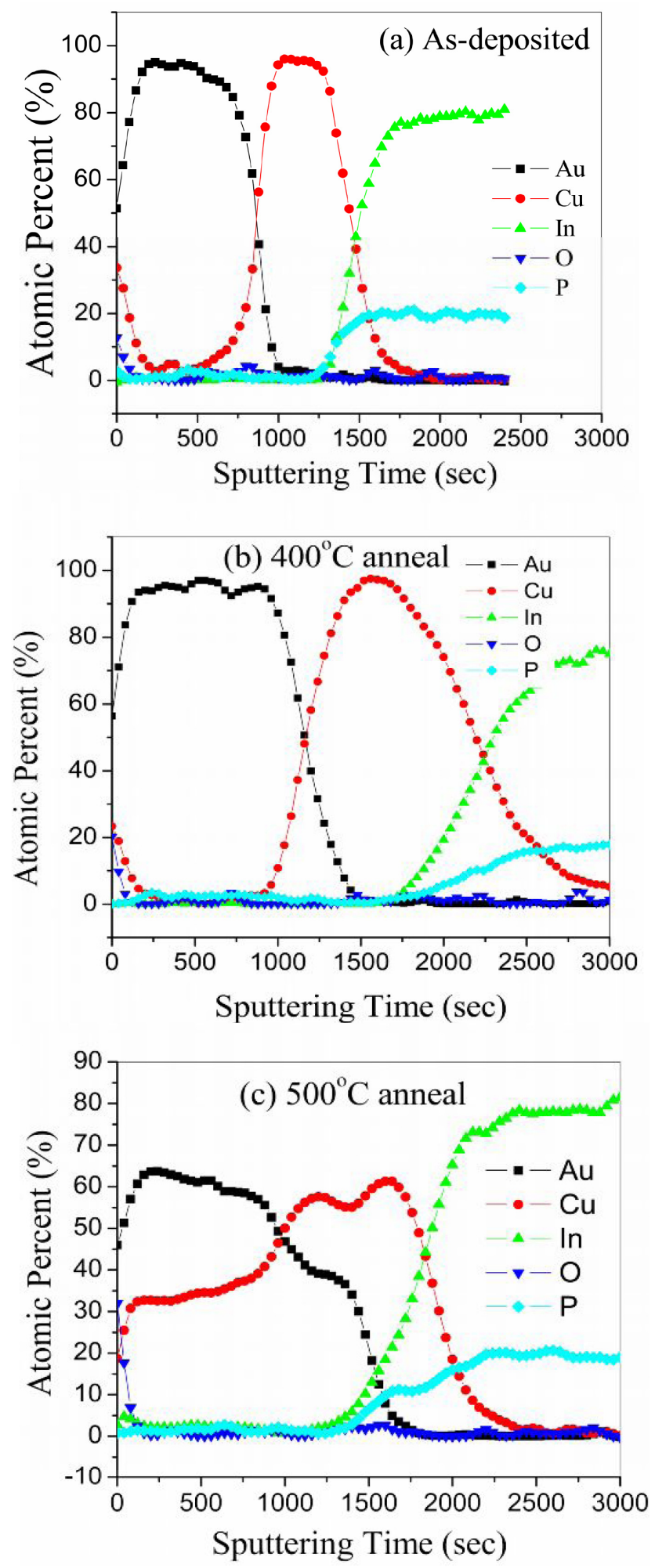

Fig. (6). AES depth profiles of $\mathrm{Au} / \mathrm{Cu} / \mathrm{n}-\mathrm{InP}$ Schottky diode: (a) asdeposited, (b) $400^{\circ} \mathrm{C}$ annealed and (c) $500^{\circ} \mathrm{C}$ annealed contacts.
In order to further confirm the interfacial reactions at the $\mathrm{Au} / \mathrm{Cu}$ and $\mathrm{InP}$ interfaces before and after annealing at $500^{\circ} \mathrm{C}, \mathrm{X}$-ray diffraction (XRD) analysis is performed. Fig. (7) shows the XRD plots of the $\mathrm{Au} / \mathrm{Cu} / \mathrm{n}-\mathrm{InP}$ Schottky diode as a function of annealing temperature. The XRD plot of the as-deposited sample is shown in Fig. (7a). In addition to the characteristic peaks of $\mathrm{Cu}$ (111), Au (111) and InP (111) (222), there are extra peaks which are observed. These peaks are identified as $\mathrm{Cu}_{2} \operatorname{In}(100)$ and $\mathrm{Cu}_{2} \operatorname{In}(300)$. For the sample annealed at $400^{\circ} \mathrm{C}$, Fig. (7b), there is an additional peak observed as compared to the as-deposited sample which is recognized as $\mathrm{Au}_{7} \mathrm{In}_{3}$ (321) (214). This indicates the formation of a new interfacial phase at the interface. Fig. (7c) shows XRD plot of the sample annealed at $500^{\circ} \mathrm{C}$. There are extra peaks which are observed compared to the as-deposited and annealed at $400^{\circ} \mathrm{C}$ samples. These peaks are identified as $\mathrm{CuP}_{2}$ (304) and $\mathrm{Au}_{2} \mathrm{P}_{3}$ (192). This is due to preferential outdiffusion of $\mathrm{P}$ and indiffusion of $\mathrm{Cu}$ and $\mathrm{Au}$ upon annealing at $500^{\circ} \mathrm{C}$ as expected from the AES depth profile (Fig. 6c). However, the peak $\mathrm{Au}_{7} \mathrm{In}_{3}$ (321) identified in the sample annealed at $400^{\circ} \mathrm{C}$ has disappeared.

The condition of the surface of metal contacts to InP plays an important role in determining the electrical properties. The surface morphology of the $\mathrm{Au} / \mathrm{Cu}$ Schottky contacts is characterized by an atomic force microscopy (AFM) before and after annealing at $500^{\circ} \mathrm{C}$ for $1 \mathrm{~min}$ in $\mathrm{N}_{2}$ atmosphere. Fig. (8) shows the AFM images of the $\mathrm{Au} / \mathrm{Cu}$ Schottky contacts as a function of the annealing temperature. The surface morphology of the as-deposited sample is fairly smooth with a root mean square (RMS) roughness of $0.841 \mathrm{~nm}$ as shown in Fig. (8a). When the contact was annealed at $400^{\circ} \mathrm{C}$, Fig. $(\mathbf{8 b})$, the surface roughness became smoother with an RMS roughness of $0.651 \mathrm{~nm}$ as compared to the as-deposited sample. However, for the sample annealed at $500^{\circ} \mathrm{C}$, Fig. $(\mathbf{8 c})$, the surface roughness slightly increased to $0.772 \mathrm{~nm}$ as compared to the sample annealed at $400^{\circ} \mathrm{C}$. This indicates that the surface morphology of $\mathrm{Au} / \mathrm{Cu} / \mathrm{n}$-InP Schottky diode did not change significantly even after annealing at $500^{\circ} \mathrm{C}$.

It is very interesting to know that the chemical reaction of the metal/InP interface, the interface chemistry between metals and semiconductor can play an important role in the electrical properties of devices. The degree of intermixing of In and $\mathrm{P}$ with the contact metal and the formation of surface states at the interface are influenced by the chemical reactivity of the metal with InP. The electrical measurements showed that the barrier height is increased for the contact annealed at $400^{\circ} \mathrm{C}$ compared with that of the as-deposited sample. However, the barrier heights decrease with an increase in annealing temperature up to $600^{\circ} \mathrm{C}$. During deposition, the $\mathrm{Cu}$ atoms diffuse easily into $\mathrm{InP}$ and result in the formation of $\mathrm{Cu}$-In intermetallic compounds as evidenced from the AES and XRD measurements. The variation in barrier heights of $\mathrm{Au} / \mathrm{Cu} / \mathrm{n}$-InP Schottky diode with annealing temperature could be explained based on the AES and XRD results. As the annealing temperature 

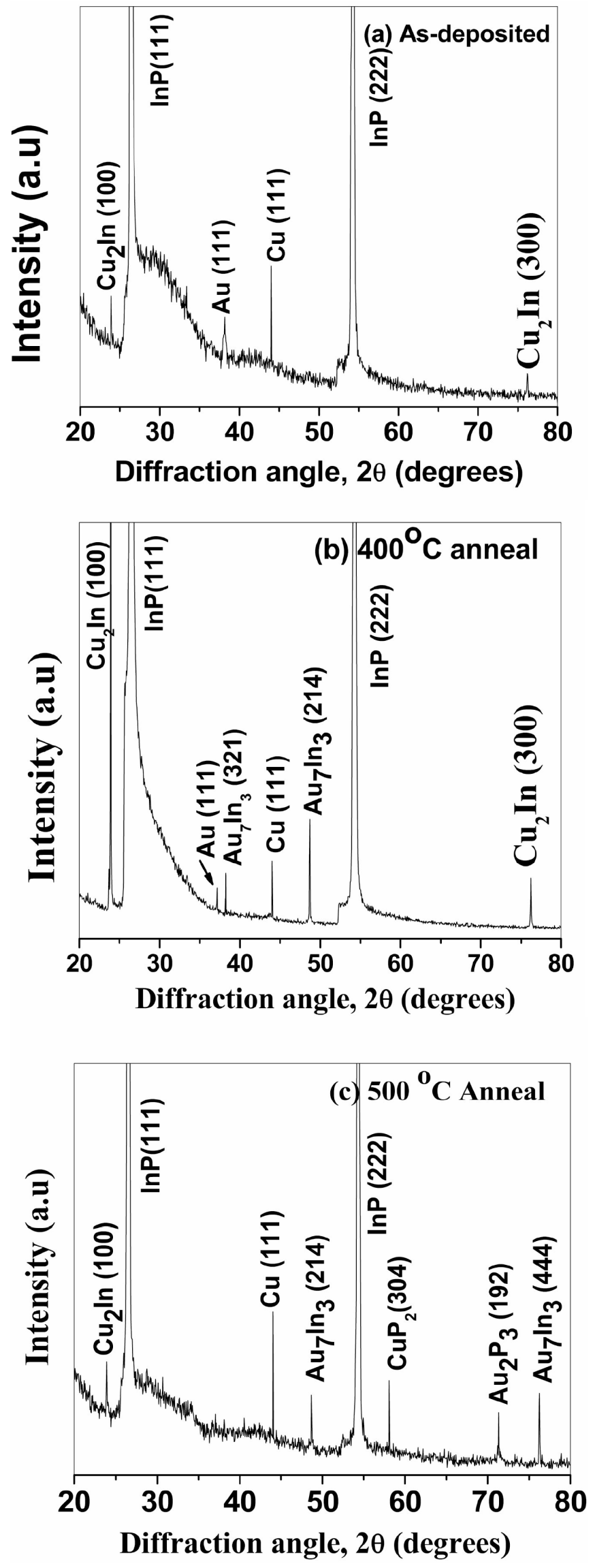

Fig. (7). XRD plots of the $\mathrm{Au} / \mathrm{Cu} / \mathrm{n}-\mathrm{InP}$ Schottky diode: (a) asdeposited, (b) $400^{\circ} \mathrm{C}$ annealed and (c) $500^{\circ} \mathrm{C}$ annealed samples.

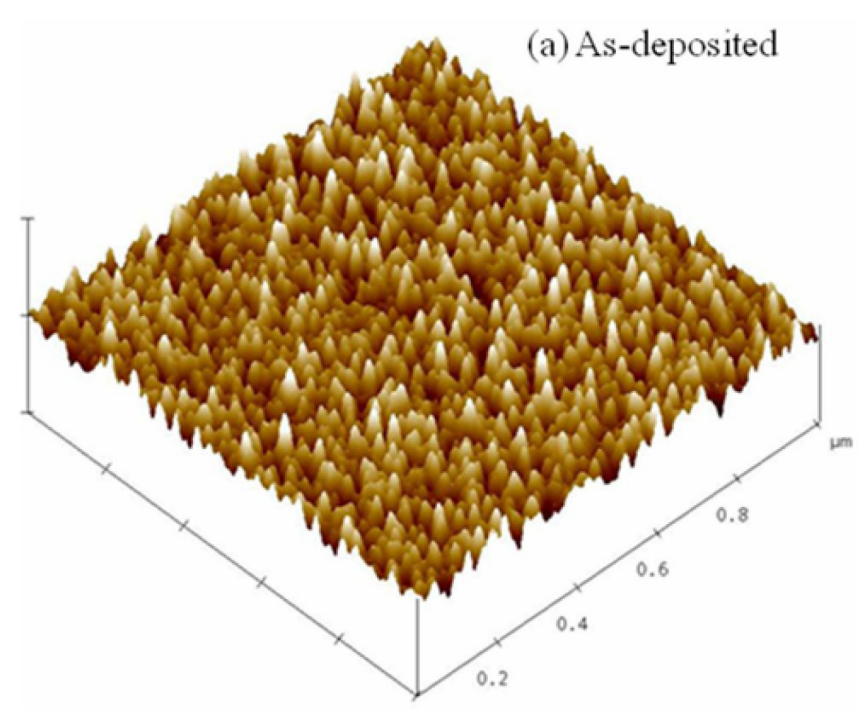

(b) $400^{\circ} \mathrm{C}$ anneal

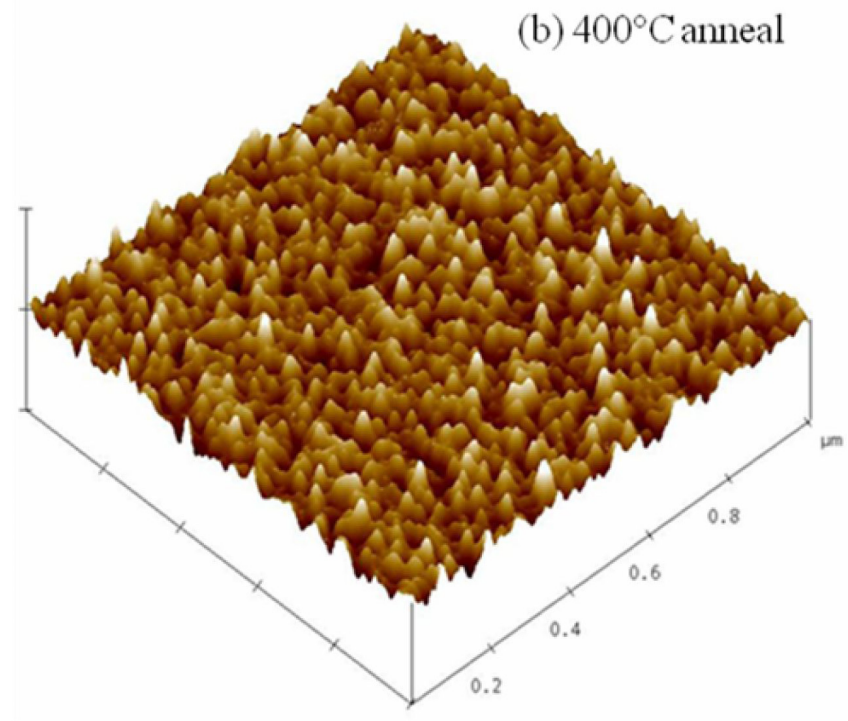

(c) $500^{\circ} \mathrm{Canneal}$

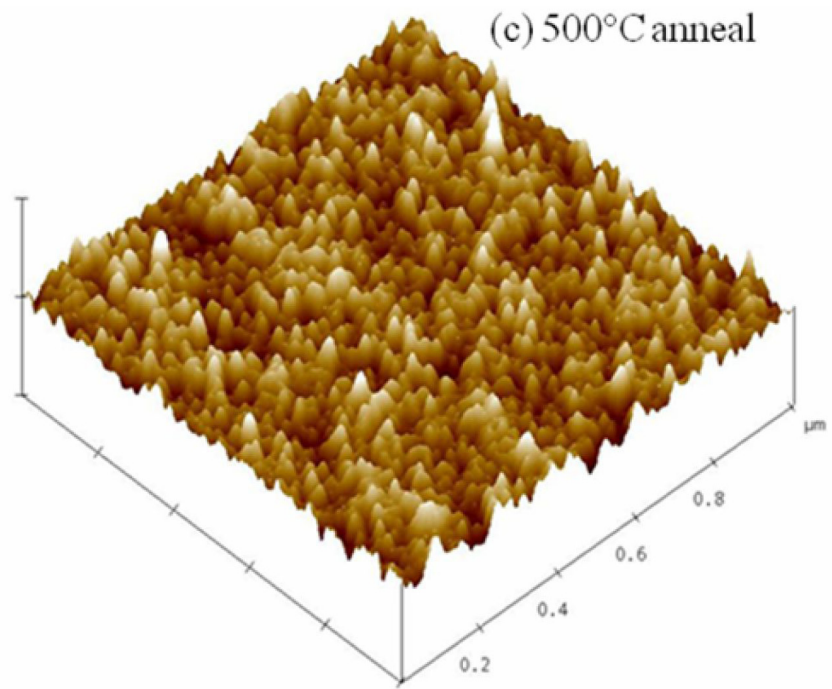

Fig. (8). AFM micrographs of the $\mathrm{Au} / \mathrm{Cu}$ Schottky contacts to ntype InP: (a) as-deposited (b) $400^{\circ} \mathrm{C}$ annealed and (c) $500^{\circ} \mathrm{C}$ annealed samples.

increases up to $400^{\circ} \mathrm{C}$, there is an interfacial region formed at the interface with the outdiffusion of indium (In) into 
$\mathrm{Au} / \mathrm{Cu}$ layers as evidenced from the AES depth profile (Fig. 6b). As a result, the formation of interfacial phases such as $\mathrm{Cu}_{2} \mathrm{In}$ (100) (300) and $\mathrm{Au}_{7} \mathrm{In}_{3}$ (321) (214) are responsible for the increase in the barrier height. The presence of these phases at the interface causes the variation in leakage current density. The increase in the SBH is always accompanied by a corresponding reduction in the reverse leakage current. The increase in barrier height may be due to the increase in negative charges at the interface. These negative charges probably arise due to electron traps located at the InP surface and associated with In vacancies created near the surface [28]. The increase in the barrier height may also be due to a modification of the surface states which generally control the barrier height in metal/III-V semiconductor systems [2]. The defects can be reduced due to the interdiffusion of metals into InP. Thus, the consumption of the defect region is followed by the increase in the value of the Schottky barrier height. However, the decrease of barrier height after annealing at $500^{\circ} \mathrm{C}$ could be attributed to the reaction of $\mathrm{Cu}$ and $\mathrm{Au}$ with $\mathrm{P}$ anion resulting in the formation of metalanion complex $\mathrm{CuP}_{2}$ (304) and $\mathrm{Au}_{2} \mathrm{P}_{3}$ (192) phases observed. These interfacial phases may have different work functions than the $\mathrm{Cu}$ and $\mathrm{Au}$ contact layer and it will affect the barrier height. The formation of phosphorous phases may create phosphorous vacancies in InP layer near the junction. These vacancies act as donors, which reduces the barrier height upon annealing [40]. The decrease in barrier height at higher annealing temperature is expected to be the result of the formation of a layer containing defects which in this case should be positively charged. The reaction process starts with the breakdown of InP and reaction of deposited metal atoms with In and $\mathrm{P}$ atoms. The $\mathrm{P}$ and $\mathrm{In}$ atoms diffuse towards the metal as the annealing temperature increases. The decrease in the barrier height is low after annealing at $500^{\circ} \mathrm{C}$ because a thermodynamically stable material such as a monophosphide phase serves as a diffusion barrier that minimizes the contact/substrate interaction not only with respect to chemical reactions but also the interdiffusion at the interface. Furthermore, Andersson-Soderberg and Ivey et al., [41, 42] noted that the possible explanation for the disappearance of $\mathrm{P}$ from the near-surface region after heat treating the sample at $500^{\circ} \mathrm{C}$ is due to the loss of volatile $\mathrm{P}$ to the atmosphere. Janardhanam et al., [22] have explained the decrease in barrier height for the $\mathrm{Mo} / \mathrm{n}$-InP after annealing at $500^{\circ} \mathrm{C}$ may be due to the formation of phosphide phases at the interface. For n-InP, however, the increase of the donor defects at the interface region would lead to the narrowing of the depletion region and hence the decrease of barrier height. The discrepancy of the SBHs of $\mathrm{Au} / \mathrm{Cu}$ Schottky contacts is mostly due to the observed structural changes of the $\mathrm{Au} / \mathrm{Cu}$ films at the interface.

\section{CONCLUSION}

In summary, the effect of rapid thermal annealing on electrical and structural properties of $\mathrm{Au} / \mathrm{Cu}$ Schottky contacts on n-InP by means of using current-voltage (I-V), capacitance-voltage (C-V), auger electron spectroscopy (AES) and X-ray diffraction (XRD) measurements. The Schottky barrier height $(\mathrm{SBH})$ of the as-deposited $\mathrm{Au} / \mathrm{Cu}$
Schottky contact is found to be $0.64 \mathrm{eV}$ (I-V) and 0.76 $\mathrm{eV}(\mathrm{C}-\mathrm{V})$, respectively. It is observed that the Schottky barrier height increases with increase in the annealing temperature up to $400^{\circ} \mathrm{C}$. Further increase in the annealing temperature up to $600^{\circ} \mathrm{C}$, the Schottky barrier height (SBH) decreases as compared with that of the $400^{\circ} \mathrm{C}$ annealed samples. The calculated series resistance $R_{s}$ of the asdeposited and annealed $\mathrm{Au} / \mathrm{Cu}$ Schottky contacts is in the range $R_{s}=307$ to $1787 \Omega$. Norde method is also used to calculate the barrier height of $\mathrm{Au} / \mathrm{Cu}$ Schottky contact. Based on the above results, the optimum annealing temperature for the $\mathrm{Au} / \mathrm{Cu}$ Schottky contact is $400^{\circ} \mathrm{C}$. According to AES and XRD results, the formation of indium phases at the interface may be the reason for the increase of barrier height after annealing at $400^{\circ} \mathrm{C}$. The formation of phosphide phases at the interface may be the reason for the decrease in barrier height for contact annealed at $500^{\circ} \mathrm{C}$. The AFM results showed that the overall surface morphology of $\mathrm{Au} / \mathrm{Cu}$ Schottky contact is fairly smooth even after annealing at $500^{\circ} \mathrm{C}$.

\section{ACKNOWLEDGEMENT}

This work was financially supported by the grant from the "Industrial Source Technology Development Programs (2009-F014-01)" of the Ministry of Knowledge Economy (MKE) of Korea.

\section{CONFLICT OF INTEREST}

\author{
Declared none.
}

\section{REFERENCES}

[1] Pearsall TP, Ed. Properties, processing and applications of indium phosphide. London: IEE 2000.

[2] Rhoderick EH, Williams RH. Metal-semiconductor contacts. Oxford: Clarandon Press 1988.

[3] Williams RH, Robinson GY. Physics and chemistry of III-V compound semiconductor interfaces. In: Wilmsen CW, Ed. New York: Plenum Press 1985.

[4] Cetin H, Ayyildiz E, Turut A. Barrier height enhancement and stability of the Au/n-InP Schottky barrier diodes oxidized by absorbed water vapor. J Vac Sci Technol B 2005; 23: 2436-43.

[5] Wilmsen CW. Physics and Chemistry of III-V compound semiconductor interfaces. New York: Lenum Press 1985.

[6] Sze SM. Physics of semiconductor devices, $2^{\text {nd }}$ ed. New York: John Wiley \& Sons 1981.

[7] Chou LJ, Hsieh KC, Wohlert DE, Cheng KY. Formation of amorphous oxide and gallium oxide on InP substrates by water vapor oxidation. J Appl Phys 1998; 84: 6932-4.

[8] He L, Anderson WA. Characteristics of oxygen implanted indium phosphide. J Vac Sci Technol A 1993; 11: 1474-9.

[9] Touhami R, Ravelet S, Yagoub MCE, Baudrand H. Influence of oxygen plasma on electrical and physical parameters of Au-oxiden-InP structures. J Appl Phys 2003; 94: 6574-8.

[10] Song YP, Van Meirhaeghe RL, Laflere WH, Cardon F. On the difference in apparent barrier height as obtained from capacitancevoltage and current-voltage-temperature measurements on $\mathrm{Al} / p$-InP Schottky barriers. Solid State Electron 1986; 29: 633-8.

[11] Werner JH, Guttler HH. Barrier inhomogenieties at schottky contacts. J Appl Phys 1991; 69: 1522-33.

[12] Mamor M, Sellai A, Bouziane K, Harthi SHAl, Busaidi MAl, Gard FS. Influence of He-ion irradiation on the characteristics of $\mathrm{Pd} / \mathrm{n}$ Si0.90Ge0.10/Si Schottky contacts. J Phys D Appl Phys 2007; 40: 1351-6.

[13] Tung RT. Electron transport at metal-semiconductor interfaces: general theory. Phys Rev B 1992; 45: 13509-23. 
[14] Sullivan JP, Tung RT, Pinto MR, Graham WR. Electron transport of inhomogeneous Schottky barriers: a numerical study. J Appl Phys 1991; 70: 7403-24

[15] Chand S, Kumar J. Effects of barrier height distribution on the behavior of a Schottky diode. J Appl Phys 1997; 82: 5005-10.

[16] Eftekhari G. Electrical characterization of rapidly annealed Ni and Pd/n-lnP Schottky diodes. Semicond Sci Technol 1995; 10: 11636.

[17] Wen-Chang H, Dong-Rong C. International workshop on junction technology 2006; p. 295.

[18] Jeng MJ, Wang HT, Chang LB, Cheng YC, Lee CI, Lin RM. Barrier height enhancement of Ni/n-Type InP Schottky contact using a thin praseodymium interlayer. Jpn J Appl Phys 1999; 38: L1382-4.

[19] Huey-Ing C, Yen-I C. A comparative study of hydrogen sensing performances between electroless plated and thermal evaporated Pd/InP Schottky diodes. Semicond Sci Technol 2003; 18: 104-10.

[20] Cetin H, Ayyildiz E. The electrical properties of metal-oxidesemiconductor devices fabricated on the chemically etched n-InP substrate. Appl Surf Sci 2007; 253: 5961-6.

[21] Bhaskar Reddy M, Janardhanam V, Ashok Kumar A, Rajagopal Reddy V, Narasimha Reddy P. Rapid thermal annealing effects on electrical and structural properties of $\mathrm{Pd} / \mathrm{Au}$ Schottky contacts to ntype InP (111). Phys Status Solidi A 2009; 206: 250-5.

[22] Janardhanam V, Ashok Kumar A, Rajagopal Reddy V, Narasimha Reddy P. Effects of annealing temperature on electrical and structural properties of Mo/n-InP (100) Schottky contacts. Surf Interface Anal 2009; 41: 905-10.

[23] Cetin H, Ayyildiz E. On barrier height inhomogeneities of Au and $\mathrm{Cu} / \mathrm{n}$-InP Schottky contacts. Physica B 2010; 405: 559-63.

[24] Sankar Naik S, Rajagopal Reddy V, Chel-Jong C, Jong-Seong B. Electrical and structural properties of double metal structure $\mathrm{Ni} / \mathrm{V}$ Schottky contacts on n-InP after rapid thermal process. J Mater Sci 2011; 46: 558-65.

[25] Chen CY, Chang L, Chang EY, Chen SH, Chang DE. Thermal stability of $\mathrm{Cu} / \mathrm{Ta} / \mathrm{GaAs}$ multilayers. Appl Phys Lett 2000; 77 : 3367-9.

[26] Shur M. Physics of semiconductor devices. Englewood Cliffs, New Jersey: Prentice Hall 1990.

[27] Duboz JY, Binet F, Laurent N, et al. GaN: processing, defects and devices. Res Soc Symp Proc 1996; 449: 1085.
[28] Crowell CR. The Richardson constant for thermionic emission in Schottky barrier diodes. Solid State Electron 1965: 8: 395-9.

[29] Cetin H, Ayyildiz E. Electrical characteristics of Au.Al, Cu/n-InP Schottky contacts formed on chemically cleaned and air-exposed nInP surface. Physica B 2007; 394: 93-9.

[30] Tung RT. Recent advances in Schottky barrier concepts. Mater Sci Eng R 2001; 35: 1-138.

[31] Cheung SK, Cheung NW. Extraction of Schottky diode parameters from forward current-voltage characteristics. Appl Phys Lett 1993; 49: $85-7$.

[32] Norde H. A modified forward I-V plot for Schottky diodes with high series resistance. J Appl Phy 1979; 50: 5052-4.

[33] Akkal B, Benamara Z, Gruzza B, Bideux L. Characterization of interface states at $\mathrm{Au} / \mathrm{InSb} / \mathrm{InP}(100)$ Schottky barrier diodes as a function of frequency. Vacuum 2000; 57: 219-8.

[34] Tataroglu A, Altindal S, Bbulbul MM. Temperature and frequency dependent electrical and dielectric properties of $\mathrm{Al} / \mathrm{SiO} 2 / \mathrm{p}-\mathrm{Si}$ (MOS) structure. Microelectron Engg 2005; 81: 140-9.

[35] Ohdomari I, Tu KN. Parallel silicide contacts. J Appl Phys 1980 ; 51:3735-9.

[36] Freeouf JL, Jackson TN, Laux SE, Woodal JM. Effective barrier heights of mixed phase contacts: size effects. Apply Phy Lett 1980; 40: 634-6.

[37] Cova P, Singh A. Temperature dependent I-V characteristics of $\mathrm{Ni} / \mathrm{n}-\mathrm{CdF}_{2}$ Schottky barrier type diodes. Solid State Electron 1990; 33: $11-9$

[38] Nicollian EH, Brews JR. MOS Physics and Technology. New York: Wiley 1982

[39] Altindal S, Karadeniz S, Tugluoglu N, Tataroglu A. The role of interface states and series resistance on the $\mathrm{I}-\mathrm{V}$ and $\mathrm{C}-\mathrm{V}$ characteristics in $\mathrm{Al} / \mathrm{SnO} 2 / \mathrm{p}-\mathrm{Si}$ Schottky diodes. Solid State Electron 2003; 41: 1847-54.

[40] Spicer WE, Lindau I, Skeath P, Su CY, Chye P. Development and confirmation of the unified model for Schottky barrier formation and MOS interface states on III-V compounds. Phy Rev Lett 1980; 44: 120 .

[41] Andersson M. Ternary phase equilibria in the (Cr, M0, W) -In-P systems at $600^{\circ} \mathrm{C}$. J Alloys Compd 1993; 198(1-2): L15-8.

[42] Soderberg MA. Phase relationship in $\mathrm{Ni} / \mathrm{InP}$ system. J Less Common Met 1991; 171: 179-86. 